\title{
Nanotechnology to the Rescue: Using nano-enabled approaches in microbiological food safety and quality
}

Mary Eleftheriadou1, Georgios Pyrgiotakis², Philip Demokritou ${ }^{2 *}$

${ }^{1}$ Department of Life Sciences, European University Cyprus

6, Diogenis St., Nicosia-Cyprus

${ }^{2}$ Center for Nanotechnology and Nanotoxicology, Harvard School of Public Health, 665 Huntington Ave, Boston, MA

*Corresponding author

665 Huntington Ave,

Room 1310B, Bldg 1,

Boston, MA, 02115

Tel: 617.432 .3481

Email: pdemokri@hsph.harvard.edu 


\section{Abstract}

Food safety and quality assurance is entering a new era. Interventions along the food supply chain must become more efficient in safeguarding public health and the environment and must address numerous challenges and new consumption trends. Current methods of microbial control to assure the safety of food and minimize microbial spoilage have each shown inefficiencies. Nanotechnology is a rapidly expanding area in the agri/feed/food sector. Nano-enabled approaches such as antimicrobial foodcontact surfaces/packaging, nano-enabled sensors for rapid pathogen/contaminant detection and nano-delivered biocidal methods, currently on the market or at a developmental stage, show great potential for the food industry. Concerns on potential risks to human health and the environment posed by use of engineered nanomaterials (ENMs) in food applications must, however, be adequately evaluated at the developmental stage to ensure consumer's acceptance. 


\section{Graphical Abstract}

\section{Nano-Enabled Methods for Food Safety \& Quality Enhancement}
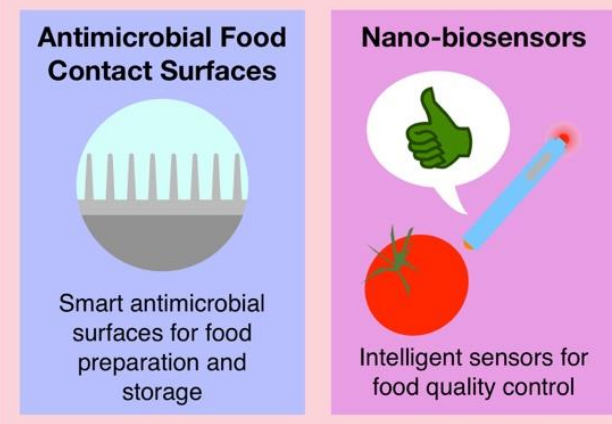

Food packaging

Engineered Water

$\mathrm{O}_{2}$, Bacteria, etc.

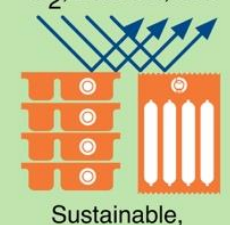

Sustainable,

biodegradable, stronger

and smart food Nanostructures

food quality control

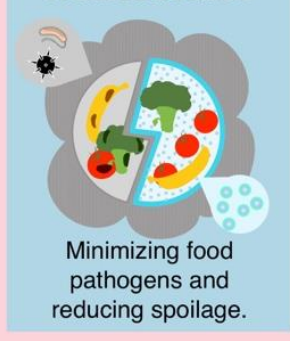




\section{INTRODUCTION}

In addition to being nutritious and appealing, food must be above all safe. Providing safe food to consumers has never been more important and more challenging for food authorities and the food industry. The worldwide toll of foodborne disease is alarming (600 million cases, 420,000 deaths each year, $[1 \bullet]$ with novel hazards emerging and reported cases increasing, while the magnitude of food spoilage is reaching epidemic levels; In the U.S., it is estimated that $30-50 \%$ of the food supply is wasted.[2]

The food production environment is facing unprecedented challenges such as the global dimension of the food chain, changes in modern production practices, increased at risk population, climate change, water shortage, and consumption trends for healthier food, with fewer preservatives, less chemicals and increased demand for organic labels. $[3 \bullet 4]$ In this complex context, safety and quality of food must be addressed alongside the demand for increased food production in an international environment with great divergence between countries and continents in terms of organization, infrastructure, legislative requirements and food protection mechanisms.[3•] A new generation of methods for food safety/ quality, especially microbial control interventions, are on the horizon to enable the food industry in addressing current inadequacies and 
consumption trends and achieve new levels of safety, sustainability and economic growth.

In this paper, the emerging area of nanotechnology and in particular, nano-enabled approaches, as they apply to microbiological food safety and quality assurance are presented, introducing the reader to nano-enabled technologies that are either currently on the market or at a research/developmental stage.

\section{Current approaches to food safety}

Food safety and quality is assured through preventative controls implemented from 'farm to plate'. The ideal scenario is to minimize risks in the consumer plate without compromising the organoleptic or nutritional qualities of the food. There are a variety of physical and chemical methods to eliminate/reduce microbial hazards in food. These include physical methods such as thermal approaches (heat, freezing, refrigerated storage), radiation (UV, gamma), filtration, drying, and chemical methods such as chlorine based compounds, ozone, hydrogen peroxide.[5] It is worth noting that, commonly used microbial control technologies rely heavily on chemicals,[6] radiation,[7] and thermal approaches,[8] all of which have significant drawbacks: i) sensory effects and degradation of quality and texture,[9] ii) high energy cost, iii) significant environmental footprint, and 
iv) serious occupational and health implications.[10] Additionally, they are not all compatible with the green/organic production philosophy and legislative requirements. $[11,12]$

The consumer trend for 'greener' and chemical free approaches, puts pressure on the food industry to develop novel, more efficient, sustainable, and low cost anti-microbial methods to replace and/or supplement existing ones so as to deal effectively with emerging hazards and the huge problem of food waste.[13] Nanotechnology is a promising technology to be utilized for food safety and quality applications.

\section{Emerging Nano-enabled approaches along the food chain}

Nanotechnology has been identified as one of the key-enabling technologies impacting all industries including the food industry.[14••] It is currently contributing significantly to the development of novel and innovative applications in the agriculture, food and feed sector (referred to as agri/food/feed). The most common applications are nano-encapsulated agrochemicals (such as nano-pesticides, fertilizers) and food additives/supplements (nano-nutraceuticals), antimicrobials/biocides and active/intelligent packaging.[15,16] Information from a recent EFSA inventory reveals the presence of 276 agri/food/feed nanotechnology applications in the market with many more under development. [17] 
Especially in regards to microbiological food safety and quality, nanoenabled applications are emerging as a very promising alternative.[18•] These include antimicrobial food contact surfaces and surface coatings using engineered nanoparticles i.e. Ag,[19] $\mathrm{ZnO},[20]$ and the photocatalytic ability of $\mathrm{TiO}_{2}$, [21] nano-enabled sensors that can very rapidly detect the presence of pathogens or other substances,[22,23] 'active/intelligent' food packaging with improved food protection properties and biodegrading abilities [14] and as surface disinfection methods.[24] Table 1 summarizes nano-enabled intervention approaches explored for food safety and quality.[25,26]

\section{Nano-enabled antimicrobial food contact surfaces}

A range of nano-enabled antimicrobial food contact surfaces and coatings can assist in maintaining hygiene during food production and storage, possessing microbial inactivation potential or prevention of microbial attachment and subsequent biofilm formation. These type of surfaces can be found in food preparation and processing facilities, kitchen and cooking ware, cutting boards, equipment, conveyer belts etc.[14] Such antimicrobial surfaces utilize nanoscale metal or metal oxides such as $\mathrm{Ag},[27 \bullet]$ photocatalytic nanoparticles (such as $\mathrm{TiO}_{2}$ and $\mathrm{ZnO}$ ),[28] and nanoscale topography that allows the creation of surfaces with anti-fouling properties.[29] 
More specifically, nanoscale silver a well-known antibacterial and one of the most commonly used metals.[30] Applications of silver embedded in biodegradable coatings can be used both for bacteria inactivation and antifouling applications. Silver nanoparticles have been integrated in agar and banana powder[31] and in gelatin,[32] and have been also combined with Graphene Oxide resulting in surfaces that inhibit almost up to $100 \%$ of bacteria attachment.[33] Silver nanoparticles are anchored on common surfaces like glass with the help of amino groups, inhibiting the formation of biofilms.[34] A notable application of silver nanoparticles was the combination with crystal violet (photo activated antimicrobial dye) into medical grade silicone, which not only achieved bacterial inactivation under visible light, but also improved under dark.[35]

In addition, among the most widely used nano-enabled antimicrobial surfaces are the various photocatalytic surfaces based on $\mathrm{TiO}_{2}, \mathrm{ZnO}, \mathrm{CeO}_{2}$ etc.[36] Photocatalysis requires light (commonly UV at $350 \mathrm{~nm}$ ) and an appropriate surface to create pairs of reactive oxygen species (ROS) that oxidize and damage organic matter, including bacteria.[37] The use of UV light is a major limitation for photocatalytic surfaces but in recent years photocatalytic NPs using visible light have been developed.[38] The most common strategies for visible light photocatalysis is the dye sensitization, [39] 
doping with elements such as $\mathrm{Cu}+$ ions, [40] and the introduction of novel materials such as bismuth vanadate $\left(\mathrm{BiVO}_{4}\right)$.[41] These materials have been recently successfully integrated into polymer matrices to create a photocatalytic film.[42]

Furthermore, the integration of natural antimicrobial extracts in various surfaces as a greener alternative to harsh chemicals has also been used in recent years. For example cinnamaldehyde was nano-encapsulated and immobilized on glass surfaces showing significant antibacterial activity against E. coli.[43] Similar results were obtained with thyme oil emulsified with soluble soybean polysaccharide (nano emulsion) and immobilized on glass surface.[44] Donsi et al. used mandarin oil nano-emulsion on an edible chitosan coating used to coat green beans.[45] Otini et al. developed antimicrobial edible composite films with pectin/papaya puree/cinnamaldehyde nano-emulsions able to inactivate various foodrelated bacteria such as E. coli, L. monocytogenes and S. enterica.[46]

Finally, many bacteria including pathogens have the ability to attach and form biofilms on surfaces in the natural environment, in industrial settings and the health care environment. These biofilms are resistant to most disinfection methods and become an important source of contamination in the food industry and hospital environment with 
tremendous implications.[47] An emerging method for the prevention of biofilms is nanoscale topography, the construction of nanoscale surfaces that can disturb the surface morphology, free energy, charge or combination thereof.

The majority of these nanostructures are made with nanolithography, typically on silicon surfaces,[48] or by nanoparticle deposition on surfaces.[49] Among the most common antifouling materials are Carbon Nanotubes,[50] mesoporous and nanoporous silica,[51,52] and Alumina.[53,54] More recently biofouling surfaces based on proteins have also been created.[55] Feng et al. utilized aluminum oxide anodization surfaces to mitigate microbial attachment and biofilm formation, with promising results. Their findings open the way to the design and fabrication of nanoporous anodized surfaces as well as other engineered affordable antifouling surfaces for the food industry. A major limitation of these surfaces is the cost and their fragile nature. $[53,54]$

\section{Food Packaging}

Nanotechnology has enabled the production of packaging that is active and intelligent with improved mechanical and thermal properties to ensure better protection of foods.[56] The integration of nano-clays in biopolymers enhanced their mechanical properties, enabling their use as an alternative 
biodegradable and eco-friendly food packaging.[57] Further to the enhancement of the mechanical properties, packaging can become a gas barrier to extend product shelf life such as limiting oxygen penetration [58] or preventing of $\mathrm{CO}_{2}$ leakage in carbonated drinks using titanium nitride nanoparticles. [59]

Nano-enabled solutions also allowed the integration of various bioactive molecules and nanoparticles to prevent oxidation and food degradation. Selenium and cellulose NPs can be integrated into food packaging to retard or inhibit the ROS that can degrade food quality.[60] The nano-encapsulation of other entities such as phenols can also provide protection against degradation, particularly of fatty foods.[61] Other essential oils can also be integrated in nanofibers $[62,63]$ to prolong the lifespan of fresh produce.

A new packaging material that has gained significant attention is nanocellulose.[64] Nanocellulose nanofibrils and nanocrystals have been incorporated as a reinforcement phase in nanocomposites.[64] Also, nano cellulose is used as a base material that is enhanced with other nanomaterials such as photocatalysts.[65] In other instances, it can be the carrier of other antimicrobial agents with controlled release.[66] 


\section{Nano-enabled sensors}

Detection of pathogens and spoilage organisms in foods takes from several hours to days using traditional culture, immunological or molecular methods. In recent years combining nanotechnology with the various available bio sensing techniques is bringing to life the so-called "nano-biosensors" which demonstrate rapid responses combined with high sensitivities. $[67,68 \bullet, 69 \bullet]$

Gold and silver nanoparticles have been used extensively as sensing platforms. A variety of gold based colorimetric and electrochemical assays have been reported for the detection of microbiological food contamination. [70] Further by changing the size and the shape of the Au nanoparticles the specificity of the detection can be fine-tuned. [71] Similarly silver nanoparticle based assays have been developed for detection of various food contaminants such as melamine, [72] pesticides [73] and various pathogens such as E. coli and Salmonella. In addition, both silver [74] and gold [75] nanoparticles were successfully implemented with Surface Enhanced Raman Spectroscopy (SERS) to detect residual pesticides.

Aptamers commonly used for toxin detection have gained popularity as the base of biosensors in food safety and quality analysis.[76] Carbon nanomaterials, namely, carbon nanotubes (CNTs), graphene quantum dots, graphene and fullerenes are gaining attention for their exciting 
properties.[77] Among them, CNTs and graphene are extensively incorporated in fabrication of sensors for food applications.[78] More recently these biosensors are being integrated into other type of structures such microcircuits and microfluidic devices. [79] [80] Although these technologies currently have low sensitivities, they are promising detection methods since they consist of inexpensive, integrated microcircuit that is easy to use.

\section{Engineered Water Nanostructures (EWNS)}

Recently, a novel nano-enabled antimicrobial platform has emerged for applications in air and on surfaces (food and fomites). This method relies on generating engineered water nano-structures (EWNS) using water by combining two different processes, electrospraying and ionization. $[24,81,82]$ The synthesized EWNS possess a unique set of physicochemical and biological properties: they are highly charged, contain Reactive Oxygen Species (ROS), are highly mobile, can remain airborne for hours, and interact and inactivate microorganisms on surfaces and in the air by delivering the ROS payload.[82] Their high surface charge makes possible the targeted delivery of the EWNS on the surface of interest, maximizing their efficiency.[24,83] In recent studies their antimicrobial potential was assessed on a representative panel of food-related microorganisms reaching inactivations up to 4 logs (99.99\% reduction) without affecting sensory 
quality of food or leaving chemical traces making it an ideal technology for chemical free applications.[83] In addition, it has very low power demands and has been shown by an acute inhalation toxicological study to possess no apparent health effects to humans when EWNS are inhaled.[82]

\section{EHS Implications of Nanomaterials}

The rapid expansion of nanotechnology in foods and the predicted further increase, raise valid concerns regarding the potential adverse effects of ENMs on human health and the environment across their life cycle. [84-87] ENMs exhibit different properties than their non-nano counterparts due to their increased surface-to-mass ratio and surface reactivity and can penetrate biological barriers and cause adverse biological responses and health outcomes. However, just like any chemical substance they are not all inherently hazardous or inherently safe.[88•]

Evidence continues to grow in terms of potential toxicological implications of ingested ENMs.[16] It is estimated that in developed countries a person ingests over 10 trillion nanoparticles per day.[18] There is therefore an urgent need to understand the relationship between pristine ENM intrinsic properties, their physico-chemical transformations across the GIT and gastrointestinal fate, their potential toxicity, as well as, their 
physicochemical and biological transformations once released into the environment. $[16,89]$

\section{Regulatory framework for nanomaterials in food}

Only within the European Union and in Switzerland the presence and use of ENMs and nanotechnology in the agri/feed/food sector needs regulatory premarket approval. In the EU, for the most part, specific provisions have been incorporated into existing regulations such as the novel foods directive (EU $257 / 87$ ) which is under revision at the moment. The aim is to demonstrate consumer and environmental safety.[90] In other parts of the world such as USA, Canada and Asia, regulation of nanomaterials in not part of a legally binding document but it rather takes the form of guidelines to the industry.[15,91•] In addition to pre market regulatory approval, the only place in the world that has a legal binding definition for ENMs, which is largely based on size, is Europe.

A key parameter that drives the regulatory framework is the consumers" perception of "nano in food". A recent study showed that although the public is skeptical of the use of nanomaterials in food (for improving safety or enhance nutrition), is in better standing compared to the GMOs. [92••] 


\section{Conclusions}

The well documented benefits of ENMs in foods will drive the commercialization of nano-enabled applications for increased food safety, quality, shelf life and improved nutrition. Antimicrobial surfaces and coatings with the potential to inactivate microorganisms or prevent biofilm formation, food packaging with improved properties for better food protection, nanosensors for rapid pathogen or contaminant detection and surface biocidal methods such as the EWNs are the major emerging nano-enabled approaches. Potential risks to humans, animals and the environment from ENMs must, however, be very well understood and addressed in parallel with the development of new materials and nano-enabled approaches. To this end, risk assessment methodologies for nanotoxicity must be urgently developed and validated, as well as, analytical methods to detect and characterize ENMs in complex food matrices. It should be stressed that we cannot extrapolate effects on ENMs based on their larger size counterparts. In addition, a consensus must be reached in terms of definitions and regulatory frameworks of ENMs to address the globality of the food chain. A successful implementation of this horizon technology will lead to environmental sustainability and global economic growth. 


\section{Acknowledgements}

The authors would like to acknowledge the NIFA/USDA grant \#2013-6702121075, the NIH grant \#1R21AI119481-01 and the NIEHS grant \#U24ES026946. 


\begin{tabular}{|c|c|c|c|c|}
\hline $\begin{array}{l}\text { Antimicrobial } \\
\text { Platform }\end{array}$ & Applications & Advantages & Limitations & References \\
\hline Photocatalysis & \multirow{3}{*}{$\begin{array}{l}\text { Food handling } \\
\text { and preparation } \\
\text { surfaces, } \\
\text { kitchenware, } \\
\text { cookware, } \\
\text { cutting boards, } \\
\text { equipment, } \\
\text { conveyer belts }\end{array}$} & $\begin{array}{l}\text { Inexpensive, } \\
\text { stable, easily } \\
\text { intergrated with } \\
\text { polymers }\end{array}$ & Requires UV & {$[36,38-40,42]$} \\
\hline $\mathrm{Ag}$ & & $\begin{array}{l}\text { Very effective, } \\
\text { easily integrated } \\
\text { on all types of } \\
\text { surfaces and } \\
\text { equipment. }\end{array}$ & $\begin{array}{l}\text { Expensive, potentially } \\
\text { toxic }\end{array}$ & {$[30,32-34,43]$} \\
\hline $\begin{array}{l}\text { Antifouling } \\
\text { surfaces }\end{array}$ & & $\begin{array}{l}\text { Preventing } \\
\text { biofilms, }\end{array}$ & $\begin{array}{l}\text { Fragile, not easy } \\
\text { commercialization }\end{array}$ & {$[32,48,49,53-55]$} \\
\hline $\begin{array}{l}\text { Emulsified } \\
\text { natural extracts }\end{array}$ & $\begin{array}{l}\text { Food coatings, } \\
\text { general purpose } \\
\text { antibacteria }\end{array}$ & $\begin{array}{l}\text { Natural extracts, } \\
\text { green chemistry }\end{array}$ & $\begin{array}{l}\text { Low efficiency, strong } \\
\text { odors, short lifetime }\end{array}$ & {$[43-46]$} \\
\hline Food Packaging & $\begin{array}{l}\text { Antimicrobial } \\
\text { media, stronger } \\
\text { packaging, } \\
\text { prevention of } \mathrm{O}_{2} \\
\text { exchange } \\
\end{array}$ & $\begin{array}{l}\text { Inexpensive, light } \\
\text { weight, } \\
\text { biodegradable }\end{array}$ & $\begin{array}{l}\text { Early stage } \\
\text { commercialization, } \\
\text { potential to } \\
\text { contaminate the food } \\
\text { with ENMs }\end{array}$ & {$[56,58,60,62,64,66]$} \\
\hline Sensors & $\begin{array}{l}\text { Quick food } \\
\text { quality check for } \\
\text { toxins and } \\
\text { pathogens }\end{array}$ & $\begin{array}{l}\text { Faster than all } \\
\text { other methods to } \\
\text { detect pathogens } \\
\text { and pesticide } \\
\text { residues }\end{array}$ & $\begin{array}{l}\text { Early stages, utilizes } \\
\text { materials with } \\
\text { potential toxic effects }\end{array}$ & {$[67,69-80]$} \\
\hline EWNS & $\begin{array}{l}\text { Usage along the } \\
\text { entire farm-to- } \\
\text { fork continuum }\end{array}$ & $\begin{array}{l}\text { Water based, } \\
\text { improves food } \\
\text { safety and quality }\end{array}$ & $\begin{array}{l}\text { Needs to be upscaled } \\
\text { for commercials } \\
\text { applications }\end{array}$ & {$[24,83]$} \\
\hline
\end{tabular}

Table 1: Summary of the major nano-enabled methods for food safety and

quality. 


\section{References}

1.. World Health Organization (WHO): WHO estimates of the global burden of foodborne diseases. World Health Organization; 2015.

This is the most comprehensive report to date estimating the global burden of foodborne diseases. The report includes estimates of the burden of foodborne diseases caused by 31 bacteria, viruses, parasites, toxins and chemicals. The estimates are based on the best available data at the time of reporting, and identified data gaps were filled using imputation, assumptions and other methods.

2. Tscharntke T, Clough Y, Wanger TC, Jackson L, Motzke I, Perfecto I, Vandermeer J, Whitbread A: Global food security, biodiversity conservation and the future of agricultural intensification. Biological Conservation 2012, 151:53-59.

3••. Uyttendaele M, Franz E, Schlüter O: Food Safety, a Global Challenge. International Journal of Environmental Research and Public Health 2016, Vol. 13, Page 67 2015, 13:67.

This editorial article belongs to the special issue on Food Safety and provides the reader with useful information on the current standing of food safety assurance in the global food chain, listing challenges and emerging hazards, as well as, opinions for a sustainable future.

4. European Food Safety Authority: Protecting consumers' health with independent scienti c advice on the food chain. 2016.

5. Parish ME, Beuchat LR, Suslow TV, Harris LJ, Garrett EH, Farber JN, Busta FF: Methods to Reduce/Eliminate Pathogens from Fresh and Fresh-Cut Produce. Comprehensive reviews in food science and food safety 2003, 2:161-173.

6. Shen C, Luo Y, Nou X, Wang Q, Millner P: Dynamic Effects of Free Chlorine Concentration, Organic Load, and Exposure Time on the Inactivation of Salmonella, Escherichia coli 0157:H7, and Non-0157 Shiga Toxin-Producing E. coli. J Food Prot 2013, 76:386-393.

7. Yaun BR, Sumner SS, Eifert JD, Marcy JE: Inhibition of pathogens on fresh produce by ultraviolet energy. Int. J Food Microbiol. 2004, 90:1-8. 
8. Kou L, Luo Y, Park E, Turner ER, Barczak A, Jurick WM II: Temperature abuse timing affects the rate of quality deterioration of commercially packaged ready-to-eat baby spinach. Part I: Sensory analysis and selected quality attributes. Postharvest Biology and Technology 2014, 91:96-103.

9. Kou L, Luo Y, Wu D, Liu X: Effects of Mild Heat Treatment on Microbial Growth and Product Quality of Packaged Fresh-Cut Table Grapes. Journal of Food Science 2007, 72:S567-S573.

10. Ruder AM: Potential Health Effects of Occupational Chlorinated Solvent Exposure. Ann. N. Y. Acad. Sci. 2006, 1076:207-227.

11. Olaimat AN, Holley RA: Factors influencing the microbial safety of fresh produce: a review. Food Microbiology 2012, 32:1-19.

12. Karaca H, Velioglu YS: Ozone Applications in Fruit and Vegetable Processing. Food Reviews International 2007, 23:91-106.

13. Newell DG, Koopmans $M$, Verhoef L, Duizer $E$, Aidara-Kane A, Sprong $H$, Opsteegh M, Langelaar M, Threfall J, Scheutz F, et al.: Food-borne diseases - The challenges of 20years ago still persist while new ones continue to emerge. Int. J Food Microbiol. 2010, 139:S3-S15.

14••. Peters RJB, Bouwmeester $H$, Gottardo S, Amenta V, Arena M, Brandhoff $P$, Marvin HJP, Mech A, Moniz FB, Pesudo LQ, et al.: Nanomaterials for products and application in agriculture, feed and food. Trends Food Sci. Tech. 2016, 54:155-164.

This review article was prepared at the request of the European Food Safety Authority (EFSA). It provides up-to-date information on Nanomaterials used in the agri/food/feed sector currently in the market or under development. This comprehensive information came from extensive literature review, company websites and questionnaires sent out to NM experts, producers and developers.

15. Aschberger K, Gottardo S, Amenta V, Arena M, Moniz FB, Bouwmeester $H$, Brandhoff $P$, Mech $A$, Pesudo LQ, Rauscher $H$, et al.:

Nanomaterials in Food - Current and Future Applications and Regulatory Aspects. J. Phys.: Conf. Ser. 2015, 617:012032.

16. Servin AD, White JC: Nanotechnology in agriculture: Next steps for understanding engineered nanoparticle exposure and risk. NanoImpact 2016, 1:9-12.

17. Peters $R$, Brandhoff $P$, Weigel $S$, Marvin $H$, Bouwmeester $H$, Aschberger 
$\mathrm{K}$, Rauscher $\mathrm{H}$, Amenta $\mathrm{V}$, Arena M, Botelho Moniz F, et al.: Inventory of Nanotechnology applications in the agricultural, feed and food sector. EFSA Supporting Publications 2014, 11.

18•. Martirosyan A, Schneider Y-J: Engineered Nanomaterials in Food: Implications for Food Safety and Consumer Health. International Journal of Environmental Research and Public Health 2016, Vol. 13, Page 67 2014, 11:5720-5750.

This is a review article on Engineered Nanomaterials (ENMS) used in food safety and quality applications with special reference to health implications arising from their ingestion in food, their toxicity profiles, and major gaps in risk assessment, analysis and regulation.

19. Kim JS, Kuk E, Yu KN, Kim J-H, Park SJ, Lee HJ, Kim SH, Park YK, Park $\mathrm{YH}$, Hwang $\mathrm{C}-\mathrm{Y}$, et al.: Antimicrobial effects of silver nanoparticles. Nanomedicine 2007, 3:95-101.

20. Espitia PJP, Soares N de FF, Coimbra JSDR, de Andrade NJ, Cruz RS, Medeiros EAA: Zinc Oxide Nanoparticles: Synthesis, Antimicrobial Activity and Food Packaging Applications. Food Bioprocess Technol 2012, 5:1447-1464.

21. Fujishima A, Rao TN, Tryk DA: Titanium dioxide photocatalysis. Journal of Photochemistry and Photobiology C: Photochemistry Reviews 2000, 1:1-21.

22. Mousavi SR, Rezaei M: Nanotechnology in agriculture and food production. J Appl Environ Biol Sci 2011, [no volume].

23. Rashidi L, Khosravi-Darani K: The Applications of Nanotechnology in Food Industry. Crit Rev Food Sci Nutr 2011, 51:723-730.

24•. Pyrgiotakis G, Vedantam P, Cirenza C, McDevitt J, Eleftheriadou M, Leonard SS, Demokritou P: Optimization of a nanotechnology based antimicrobial platform for food safety applications using Engineered Water Nanostructures (EWNS). Sci. Rep. 2016, doi:10.1038/srep21073.

This paper presents the application of a newly developed method that is using just water to inactivate bacteria on the surface of fruits. The promise of this technology lies with in its ability to leave no chemical residue and the very low energy consumption.

25. Madhuri Sharon1 AKC, Kumar2 R: Nanotechnology in Agricultural Diseases and Food Safety. Journal of Phytology 2010, 2. 
26. Duncan TV: Applications of nanotechnology in food packaging and food safety: Barrier materials, antimicrobials and sensors. $J$. Colloid Interface Sci. 2011, 363:1-24.

27•. Azlin-Hasim S, Cruz-Romero MC, Ghoshal T, Morris MA, Cummins E, Kerry JP: Application of silver nanodots for potential use in antimicrobial packaging applications. Innovative Food Science \& Emerging Technologies 2015, 27:136-143.

A recent article presenting a novel applications of Ag Nanodots in food packaging applications and some preliminary promissing results.

28. Hatamie A, Khan A, Golabi M, Turner APF, Beni V, Mak WC, Sadollahkhani A, Alnoor $\mathrm{H}$, Zargar B, Bano $S$, et al.: Zinc Oxide Nanostructure-Modified Textile and Its Application to Biosensing, Photocatalysis, and as Antibacterial Material. Langmuir 2015, 31:10913-10921.

29. Barish JA, Goddard JM: Anti-fouling surface modified stainless steel for food processing. Food and Bioproducts Processing 2013, 91:352-361.

30. Rai M, Yadav A, Gade A: Silver nanoparticles as a new generation of antimicrobials. Biotechnol. Adv. 2009, 27:76-83.

31. Orsuwan A, Shankar S, Wang L-F, Sothornvit R, Rhim J-W:

Preparation of antimicrobial agar/banana powder blend films reinforced with silver nanoparticles. Food Hydrocolloids 2016, $60: 476-485$.

32. Kanmani P, Rhim J-W: Physicochemical properties of gelatin/silver nanoparticle antimicrobial composite films. Food Chemistry 2014, 148:162-169.

33. de Faria AF, Martinez DST, Meira SMM, de Moraes ACM, Brandelli A, Filho AGS, Alves OL: Anti-adhesion and antibacterial activity of silver nanoparticles supported on graphene oxide sheets. Colloids Surf. B 2014, 113:115-124.

34. Taglietti A, Arciola CR, D'Agostino A, Dacarro G, Montanaro L, Campoccia D, Cucca L, Vercellino M, Poggi A, Pallavicini $P$, et al.: Antibiofilm activity of a monolayer of silver nanoparticles anchored to an amino-silanized glass surface. Biomaterials 2014, 35:1779-1788.

35. Noimark S, Weiner J, Noor N, Allan E, Williams CK, Shaffer MSP, Parkin 
IP: Antimicrobial Surfaces: Dual-Mechanism Antimicrobial Polymer-ZnO Nanoparticle and Crystal Violet-Encapsulated Silicone (Adv. Funct. Mater. 9/2015). Adv. Funct. Mat. 2015, 25:1366-1366.

36. Gamage J, Zhang Z, Gamage J, Zhang Z: Applications of Photocatalytic Disinfection. International Journal of Photoenergy 2010, 2010:1-11.

37. Hoffmann MR, Martin ST, Choi WY, Bahnemann DW: Environmental Applications of Semiconductor Photocatalysis. Chem. Rev. 1995, 95:69-96.

38. Banerjee S, Pillai SC, Falaras P, O'Shea KE, Byrne JA, Dionysiou DD: New Insights into the Mechanism of Visible Light Photocatalysis. J. Phys. Chem. Lett. 2014, 5:2543-2554.

39. Aponiene K, Luksiene Z: Effective combination of LED-based visible light, photosensitizer and photocatalyst to combat Gram (-) bacteria. Journal of Photochemistry 1\& Photobiology, B: Biology 2015, 142:257-263.

40. Yadav HM, Otari SV, Koli VB, Mali SS, Hong CK, Pawar SH, Delekar SD: Preparation and characterization of copper-doped anatase TiO2 nanoparticles with visible light photocatalytic antibacterial activity. Journal of Photochemistry and Photobiology a-Chemistry 2014, 280:32-38.

41. Booshehri AY, Goh SC-K, Hong J, Jiang R, Xu R: Effect of depositing silver nanoparticles on Bivo 4 in enhancing visible light photocatalytic inactivation of bacteria in water. Journal of Materials Chemistry A 2014, 2:6209-6217.

42. Weng X, van Niekerk J, Neethirajan S, Warriner K: Characterization of antimicrobial efficacy of photocatalytic polymers against food-borne biofilms. LWT - Food Science and Technology 2016, 68:1-7.

43. Noimark S, Allan E, Parkin IP: Light-activated antimicrobial surfaces with enhanced efficacy induced by a dark-activated mechanism. Chem. Sci. 2014, 5:2216-2223.

44. Wu J-E, Lin J, Zhong Q: Physical and antimicrobial characteristics of thyme oil emulsified with soluble soybean polysaccharide. Food Hydrocolloids 2014, 39:144-150. 
45. Donsì $F$, Marchese $E$, Maresca $P$, Pataro G, Vu KD, Salmieri S, Lacroix M, Ferrari G: Green beans preservation by combination of a modified chitosan based-coating containing nanoemulsion of mandarin essential oil with high pressure or pulsed light processing. Postharvest Biology and Technology 2015, 106:21-32.

46. Otoni CG, Moura MR de, Aouada FA, Camilloto GP, Cruz RS, Lorevice MV, Soares N de FF, Mattoso LHC: Antimicrobial and physicalmechanical properties of pectin/papaya puree/cinnamaldehyde nanoemulsion edible composite films. Food Hydrocolloids 2014, 41: $188-194$.

47. Kumar CG, Anand SK: Significance of microbial biofilms in food industry: a review. Int. J Food Microbiol. 1998, 42:9-27.

48. Gule NP, Begum NM, Klumperman B: Advances in biofouling mitigation: A review. Critical Reviews in Environmental Science and Technology 2016, 46:535-555.

49. Ong CS, Goh PS, Lau WJ, Misdan N, Ismail AF: Nanomaterials for biofouling and scaling mitigation of thin film composite membrane: A review. Desalination 2016, 393:2-15.

50. Wu H, Tang B, Wu P: Optimization, characterization and nanofiltration properties test of MWNTs/polyester thin film nanocomposite membrane. Journal of Membrane Science 2013, 428:425-433.

51. Bao M, Zhu G, Wang L, Wang M, Gao C: Preparation of monodispersed spherical mesoporous nanosilica-polyamide thin film composite reverse osmosis membranes via interfacial polymerization. Desalination 2013, 309:261-266.

52. Wu H, Tang B, Wu P: Optimizing polyamide thin film composite membrane covalently bonded with modified mesoporous silica nanoparticles. Journal of Membrane Science 2013, 428:341-348.

53. Feng G, Cheng Y, Wang S-Y, Borca-Tasciuc DA, Worobo RW, Moraru CI: Bacterial attachment and biofilm formation on surfaces are reduced by small-diameter nanoscale pores: how small is small enough? npj Biofilms and Microbiomes 2015, 1:15022.

54. Feng G, Cheng Y, Wang S-Y, Hsu LC, Feliz Y, Borca-Tasciuc DA, Worobo RW, Moraru CI: Alumina surfaces with nanoscale topography reduce attachment and biofilm formation by Escherichia coliand Listeriaspp. Biofouling 2014, 30:1253-1268. 
55. Xia S, Cartron M, Morby J, Bryant DA, Hunter CN, Leggett GJ:

Fabrication of Nanometer- and Micrometer-Scale Protein Structures by Site-Specific Immobilization of Histidine-Tagged Proteins to Aminosiloxane Films with Photoremovable ProteinResistant Protecting Groups. Langmuir 2016, 32:1818-1827.

56. Khalaj M-J, Ahmadi H, Lesankhosh R, Khalaj G: Study of physical and mechanical properties of polypropylene nanocomposites for food packaging application: Nano-clay modified with iron nanoparticles. Trends Food Sci. Tech. 2016, 51:41-48.

57. Ghanbarzadeh B, Oleyaei SA, Almasi H: Nanostructured Materials Utilized in Biopolymer-based Plastics for Food Packaging Applications. Crit Rev Food Sci Nutr 2013, 55:1699-1723.

58. Rešček A, Ščetar M, Hrnjak-Murgić Z, Dimitrov N, Galić K: Polyethylene/polycaprolactone nanocomposite films for food packaging modified with magnetite and casein: oxygen barrier, mechanical and thermal properties. Polymer-Plastics Technology and Engineering 2016, doi:10.1080/03602559.2016.1163606.

59. EFSA Panel on food contact materials, enzymes, flavourings and processing aids (CEF): Scientific Opinion on the safety evaluation of the substance, titanium nitride, nanoparticles, for use in food contact materials. EFSA Journal 2012, 10:2641-2649.

60. Vera P, Echegoyen Y, Canellas E, Nerín C, Palomo M, Madrid Y, Cámara $C$ : Nano selenium as antioxidant agent in a multilayer food packaging material. Anal. Bioanal. Chem. 2016, doi: $10.1007 / \mathrm{s} 00216-016-9780-9$.

61. Liu F, Avena-Bustillos RJ, Chiou B-S, Li Y, Ma Y, Williams TG, Wood DF, McHugh TH, Zhong F: Controlled-release of tea polyphenol from gelatin films incorporated with different ratios of free/nanoencapsulated tea polyphenols into fatty food simulants. Food Hydrocolloids 2017, 62:212-221.

62. Wen $P$, Zhu $D-H$, Wu $H$, Zong $M-H$, Jing $Y-R$, Han $S-Y$ : Encapsulation of cinnamon essential oil in electrospun nanofibrous film for active food packaging. Food Control 2016, 59:366-376.

63. Yao Z-C, Chang M-W, Ahmad Z, Li J-S: Encapsulation of rose hip seed oil into fibrous zein films for ambient and on demand food preservation via coaxial electrospinning. J Food Eng 2016, 191:115-123. 
64. Azeredo HMC, Rosa MF, Mattoso LHC: Nanocellulose in bio-based food packaging applications. Industrial Crops and Products 2016, doi:10.1016/j.indcrop.2016.03.013.

65. El-Wakil NA, Hassan EA, Abou-Zeid RE, Dufresne A: Development of wheat gluten/nanocellulose/titanium dioxide nanocomposites for active food packaging. Carbohydrate Polymers 2015, 124:337346.

66. Sundaram J, Pant J, Goudie MJ, Mani S, Handa H: Antimicrobial and Physicochemical Characterization of Biodegradable, Nitric Oxide-Releasing Nanocellulose-Chitosan Packaging Membranes. J. Agric. Food Chem. 2016, 64:5260-5266.

67. Malhotra BD, Srivastava S, Augustine S: Biosensors for Food Toxin Detection: Carbon Nanotubes and Graphene. MRS Proceedings 2015, 1725: mrsf14-1725-i05-02.

$68 \bullet \bullet$. Li Z, Yu Y, Li Z, Wu T: A review of biosensing techniques for detection of trace carcinogen contamination in food products. Anal. Bioanal. Chem. 2015, 407:2711-2726.

This review presents the state of the art in separation and determination methods for analyzing carcinogen contamination. The review also outlines the critical challenges and future perspectives. It includes nanomaterials, imprinted polymers, and microdevices is detailed.

69•. Reverté $L$, Prieto-Simón $B$, Campàs $M$ : New advances in electrochemical biosensors for the detection of toxins: Nanomaterials, magnetic beads and microfluidics systems. A review. Anal. Chim. Acta 2016, 908:8-21.

A comprehensive review of the recent advances in biosensors used for the detection of toxins and pesticides. The review covers everything from nanoparticle sensors to microfluidics and printed systems.

70. Wang Y, Alocilja EC: Gold nanoparticle-labeled biosensor for rapid and sensitive detection of bacterial pathogens. Journal of Biological Engineering 2015 9:1 2015, 9:1.

71. Verma MS, Chen PZ, Jones L, Gu FX: Controlling "chemical nose" biosensor characteristics by modulating gold nanoparticle shape and concentration. Sensing and Bio-Sensing Research 2015, 5:13-18.

72. Song J, Wu F, Wan Y, Ma L: Colorimetric detection of melamine in pretreated milk using silver nanoparticles functionalized with 
sulfanilic acid. Food Control 2015, 50:356-361.

73. He Y, Xu B, Li W, Yu H: Silver Nanoparticle-Based Chemiluminescent Sensor Array for Pesticide Discrimination. J. Agric. Food Chem. 2015, 63:2930-2934.

74. Ankamwar B, Sur UK, Das P: SERS study of bacteria using biosynthesized silver nanoparticles as the SERS substrate. Analytical Methods 2016, 8:2335-2340.

75. Luo H, Huang Y, Lai K, Rasco BA, Fan Y: Surface-enhanced Raman spectroscopy coupled with gold nanoparticles for rapid detection of phosmet and thiabendazole residues in apples. Food Control 2016, 68:229-235.

76. Rhouati A, Yang C, Hayat A, Marty J-L: Aptamers: A Promising Tool for Ochratoxin A Detection in Food Analysis. Toxins 2013, 5:1988-2008.

77. Jariwala D, Sangwan VK, Lauhon LJ, Marks TJ, Hersam MC: Carbon nanomaterials for electronics, optoelectronics, photovoltaics, and sensing. Chem Soc Rev 2013, 42:2824-2860.

78. Abbaspour A, Norouz-Sarvestani F, Noori A, Soltani N: Aptamerconjugated silver nanoparticles for electrochemical dualaptamer-based sandwich detection of staphylococcus aureus. Biosens Bioelectron 2015, 68:149-155.

79. Xu M, Wang R, Li Y: Rapid detection of Escherichia coli 0157:H7 and Salmonella Typhimurium in foods using an electrochemical immunosensor based on screen-printed interdigitated microelectrode and immunomagnetic separation. Talanta 2016, 148:200-208.

80. Kim G, Moon J-H, Moh C-Y, Lim J-G: A microfluidic nano-biosensor for the detection of pathogenic Salmonella. Biosensors and Bioelectronic 2015, 67:243-247.

81. Pyrgiotakis G, McDevitt J, Yamauchi T, Demokritou P: A novel method for bacteria inactivation using Engineered Water Nanostructures. J. Nanopart. Res. 2012, 14:1027-1038.

82. Pyrgiotakis G, McDevitt J, Bordini A, Diaz E, Molina R, Watson C, Deloid G, Lenard S, Fix N, Mizuyama Y, et al.: A chemical free, nanotechnology-based method for airborne bacterial inactivation using engineered water nanostructures. Environ. Sci.: 
Nano 2014, 1:15-26.

83. Pyrgiotakis $G$, Vasanthakumar $A$, Gao $Y$, Eleftheriadou $M$, Toledo $E$, DeAraujo A, McDevitt J, Han T, Mainelis G, Mitchell R, et al.:

Inactivation of Foodborne Microorganisms Using Engineered Water Nanostructures (EWNS). Environ. Sci. Technol. 2015, 49:3737-3745.

84. Cohen JM, Teeguarden JG, Demokritou P: An integrated approach for the in vitro dosimetry of engineered nanomaterials. Part. Fibre Toxicol. 2014, 11:20.

85. Bolt HM, Marchan R, Hengstler JG: Recent developments in nanotoxicology. Arch. Toxicol. 2012, doi:10.1007/s00204-012-08511.

86. Oberdörster G, Oberdorster E, Oberdörster J: Nanotoxicology: an emerging discipline evolving from studies of ultrafine particles. Environ. Health Perspect. 2005, 113:823-839.

87. Lewinski N, Colvin V, Drezek R: Cytotoxicity of nanoparticles. Small 2008, 4:26-49.

88•. Boverhof DR, Bramante CM, Butala JH, Clancy SF, Lafranconi M, West J, Gordon SC: Comparative assessment of nanomaterial definitions and safety evaluation considerations. Regulatory Toxicology and Pharmacology 2015, 73:137-150.

For the interested reader this paper presents the current state of nanomaterials EHS with emphasis on the size limits used in different definitions pointing out inconsistent and considerations of other properties, including agglomerates and aggregates, distributional thresholds, novel properties, and solubility.

89. Ma X, Wang Q, Rossi L, Ebbs SD, White JC: Multigenerational exposure to cerium oxide nanoparticles: Physiological and biochemical analysis reveals transmissible changes in rapid cycling Brassica rapa. NanoImpact 2016, 1:46-54.

90. European Parliament and Council Regulation: Commission Regulation (EC) No 1852/2001 of 20 September 2001 laying down detailed rules for making certain information available to the public and for the protection of information submitted pursuant to European Parliament and Council Regulation (EC) No 257/87. OPOCE; 2001.

91••. Amenta V, Aschberger K, Arena M, Bouwmeester H, Botelho Moniz F, 
Brandhoff P, Gottardo S, Marvin HJP, Mech A, Quiros Pesudo L, et al.: Regulatory aspects of nanotechnology in the agri/feed/food sector in EU and non-EU countries. Regulatory Toxicology and Pharmacology 2015, 73:463-476.

This article focuses on the regulatory aspects of Engineered Nanomaterials in the agri/food/feed sector on worldwide basis with special reference to the European approach. It touches on NM definitions and pre-market approval divergences among regions, as well as, current gaps in regulatory provisions to address potential risks to consumer and the environment.

92••. Yue C, Zhao S, Kuzma J: Heterogeneous Consumer Preferences for Nanotechnology and Genetic-modification Technology in Food Products. J Agric Econ 2014, 66:308-328.

This study investigates heterogeneous consumer preferences for nanofood and genetically-modified (GM) food and the associated benefits. The study generates deeper insights into the diversified public acceptance of nano-food and GM food and draws comparisons among them. 